\title{
APRESENTANDO O ARTESANATO COMO TEMA SOCIAL PARA ENSINAR CIÊNCIAS/QUÍMICA POR UMA PERSPECTIVA FREIREANA
}

\author{
Jaime Rodrigues da Silva ${ }^{1}$ \\ Marlene Rios Melo2 \\ Maria de Lara Palmeira de Macedo Arguelho3
}

\section{RESUMO}

O presente artigo é parte integrante da dissertação de mestrado apresentada ao Programa de Pós-Graduação em Ensino de Ciências e Matemática da Universidade Federal de Sergipe (PPGECIMA/UFS). A pesquisa ocorreu em uma escola pública urbano-rural alagoana, cuja abordagem metodológica envolveu um Caso (SÁ; QUEIROZ, 2010) escrito para refletir sobre a escassez da Taboa (Typha domingensis), planta herbácea e perene, encontrada nos alagadiços próximos da cidade de Penedo. O objetivo foi estudar as possibilidades e limitações da inserção do artesanato, como tema social, para promover o ensino/aprendizagem de ciências/química, além de verificar a capacidade de tomada de decisão dos estudantes frente a um problema de relevância para a comunidade. Um questionário foi aplicado para levantar as impressões que os estudantes traziam sobre o artesanato, seguido da apresentação do Caso (CS) e de perguntas sobre as implicações sociais, econômicas e ambientais relacionadas com 0 desaparecimento do vegetal no ecossistema da região. Nossa análise, baseada em Bardin (1977), permitiu constatar que o ensino tradicional, mecanicista, racionalista, com memorização de fórmulas e conteúdos (DA SILVA, 2016) dificulta que os aprendizes exercitem a oralidade e construam textos mais consistentes, abrangentes e reflexivos. Nesse sentido, o estudo apresenta-se como alternativa para professores e estudantes, seja para romper com a educação bancária (FREIRE, 1997) e/ou exercitar a cidadania (DEMO, 1995, 2007), utilizando-se da contextualização (WARTHA et al., 2013) e da abordagem CTS (SILVA; DE CARVALHO, 2016) para sustentar os aspectos principais do CS.

Palavras-chave: Ensino de Ciências. Artesanato. Caso.

\footnotetext{
1 Mestre em Ensino de Ciências e Matemática (UFS). Mestre em Química Analítica Ambiental (UFS). Professor de Educação Básica, nas Secretarias de Educação de Alagoas (Penedo) e Sergipe (Capela). Graduando em Ciências da Religião (UFS). Orcid iD: https://orcid.org/0000-0002-9958-7846. E-mail: profjaimersilva@gmail.com

2 Doutora em Educação (USP). Mestre em Química Inorgânica (Unicamp). Bacharel em Química Tecnológica (USP). Licenciada em Química (Faculdade Oswaldo Cruz-SP). Professora associada da Universidade Federal do Rio Grande (FURG). Professora colaboradora do Programa de Pós-Graduação em Educação em Ciências, Química para a Vida e Saúde. Orcid iD: https://orcid.org/0000-0002-0918-784X. E-mail: marlenemelo@terra.com.br

3 Doutora em Ciências (USP). Mestre em Ciências (USP). Bacharel em Química (UFMS). Professora associada na Universidade Federal de Sergipe (UFS). Orcid iD: https://orcid.org/0000-0003-3228-6640. E-mail: larapalm@yahoo.com
} 


\title{
PRESENTING HANDICRAFT AS A SOCIAL THEME TO TEACH SCIENCES / CHEMISTRY FOR A FREIREANA PERSPECTIVE
}

\begin{abstract}
This article is part of the dissertation presented at Programa de Pós-Graduação em Ensino de Ciências e Matemática at the Universidade Federal de Sergipe (UFS/PPGECIMA). The search took place in a urban-rural public school alagoana, whose methodological approach involved a Case (SÁ; Queiroz, 2010) written to reflect about the scarcity of Cattail (Typha domingensis), herbaceous and perennial plant found in swamps near the city of Penedo. The objective was to study the possibilities and limitations of the insertion of the craft, as social theme, to promote the teaching/learning of Sciences/Chemistry, in addition to checking the decisionmaking capacity of students facing a problem of relevance for the community. A questionnaire was applied to lift the prints that students brought about the craft, followed by the presentation of the case (CS) and questions about the social, economic and environmental implications related to the disappearance of the vegetable in the the region's ecosystem. Our analysis, based in Bardin (1977), has shown that the traditional teaching, rationalist, mechanistic, with memorization of formulas and content (DA SILVA, 2016) hinders that apprentices exercise orality and build more consistent texts, comprehensive and reflective. In this sense, the study presents itself as an alternative for teachers and students, is to break with the banking education (FREIRE, 1997) and/or exercising citizenship (DEMO, 1995, 2007), using the contextualization (WARTHA et al., 2013) and STS (Science, Techonology and Society) approach (SILVA; DE CARVALHO, 2016) to support the main aspects of the CS.
\end{abstract}

Keywords: Teaching Science. Crafts. Case.

\section{PRESENTANDO EL ARTESANATO COMO TEMA SOCIAL PARA ENSEÑAR CIENCIAS/ QUÍMICA POR UNA PERSPECTIVA FREIREANA}

\section{RESUMEN}

Este artículo es parte de la tesis doctoral presentada en el Programa de PósGraduação em Ensino de Ciências e Matemática de la Universidade Federal de Sergipe (UFS/PPGECIMA). La búsqueda llevó a cabo en una escuela pública urbana y rural alagoana, cuyo enfoque metodológico implicó un caso (SÁ; Queiroz, 2010) escrito para reflexionar sobre la escasez de totora (Typha domingensis), planta herbácea y perenne que se encuentra en pantanos cerca de la ciudad de Penedo. El objetivo fue estudiar las posibilidades y limitaciones de la inserción de la artesanía, como tema social, para promover el enseñanza y el aprendizaje de las Ciencias/química, además de comprobar la capacidad de toma de decisiones de los estudiantes frente a un problema de relevancia para la comunidad. Se aplicó un cuestionario para levantar las huellas que estudiantes traídos sobre el arte, seguido por la presentación de lo Caso (CS) y preguntas sobre las implicaciones sociales, económicas y ambientales relacionadas con la desaparición de los vegetales en la 
ecosistema de la región. Nuestro análisis, basado en Bardin (1977), ha demostrado que la enseñanza tradicional, racionalista, mecanicista, con memorización de fórmulas y contenido (DA SILVA, 2016) impide que aprendices ejercen de oralidad y construcción textos más coherentes, comprensivo y reflexivo. En este sentido, el estudio se presenta como una alternativa para los profesores y estudiantes, es romper con la educación bancaria (FREIRE, 1997) o ejercicio de la ciudadanía (DEMO, 1995, 2007), utilizando la contextualización (WARTHA et al., 2013) y el enfoque de CTS (SILVA; DE CARVALHO, 2016) para apoyar los aspectos principales de la CS.

Palabras clave: Enseñanza de las ciências. Artesania. Caso.

\section{INTRODUÇÃO}

Reconhecemos e aceitamos, como meta no processo educativo, a necessidade de renovação do Ensino de Ciências da Natureza e concordamos que a formação dos professores, muitas vezes carregada de visões deformadas, constitui um entrave para a mudança. Portanto, é urgente modificar a oferta das disciplinas nos cursos de licenciatura, buscando construir competências e habilidades de uma formação docente coerente com os saberes, conhecimentos e metodologias de ensino, que levem a formação da cidadania.

Nesse sentido, Barolli e Villani (2016) alertam para a qualificação dos professores como critério para modificar os índices educacionais. Bedin e Del Pino (2019) destacam que, geralmente, os cursos de Licenciatura em Química priorizam à formação do químico e ignoram a do professor de química. Entretanto, outros trabalhos direcionam a discussão na qualidade do que se ensina aos graduandos (DE CARVALHO, 2005; DE CARVALHO; GILPÉREZ, 2006; DE CARVALHO; GONÇALVES, 2013; GATTI, 2016; MELO; VILLANI, $2011)$.

Pesquisadores têm descrito alguns dos problemas existentes no processo de ensino/aprendizagem (CACHAPUZ; GIL-PÉREZ; DE CARVALHO, 2005; DE CARVALHO; GIL-PÉREZ, 2006; GEHLEN; DELIZOICOV, 2016; MARCONDES, 2016), com destaque para: as visões distorcidas do processo constitutivo, que repassa uma verdade absoluta construída por homens dotados de extrema inteligência e que vivem à margem da sociedade; uma aprendizagem conceitual simples, que não considera a existência de 
concepções alternativas (POZO; CRESPO, 2009) e que torna a aprendizagem merecedora de reflexão e pesquisa; interpretações romantizadas da experimentação (GUIMARÃES et al., 2018) e da melhoria da aprendizagem; currículo escolar apoiado em conceitos e apresentados de forma fragmentada e descontextualizada da realidade, não levando em consideração as inter-relações entre a ciência, a tecnologia e a sociedade (LIMA JÚNIOR et al., 2014; MARCONDES et al., 2016); docentes praticantes do Discurso do Mestre (VILLANI; BAROLLI, 2006), que reforça o modelo de ensino tecnicista apoiado na memorização de fórmulas, com avaliações distantes da vivência cotidiana do aprendiz e que precisa ser alterado para uma ação mais crítica, resultando em uma melhor formação para a cidadania.

Apoiados nestas problemáticas, apresentaremos alguns pontos de reflexão na educação em ciências, para então construir nossa questão de pesquisa. Discutiremos, brevemente, sobre a necessidade da utilização da contextualização social e crítica, bem como de um currículo apoiado na perspectiva CTS. Concluímos, que o Caso (CS) representa uma boa estratégia de trabalho, mas que necessita de adequação para diferentes realidades.

\section{O CONTEXTO DA PESQUISA}

A cidade de Penedo, no estado de Alagoas, cresceu e se desenvolveu as margens do Rio São Francisco. Em 1501, com a chegada de Américo Vespúcio, o "Velho Chico" passou a ser considerado a principal entrada para o sertão. Ao longo do tempo, Penedo sobreviveu a vários conflitos e a opção da Coroa Portuguesa pelo cultivo da cana-de-açúcar, como estratégia para povoar e defender o território, colocou em contato diferentes saberes, conhecimentos e culturas, seja de europeus (principalmente, portugueses e holandeses), africanos e indígenas, que deixaram muitos ensinamentos, como por exemplo, as atividades manuais do artesanato.

O artesanato possui grande potencial para promover reflexões sobre o Multiculturalismo e o Interculturalismo Crítico (DE SANT'ANA et al., 2019), que 
podem ser relacionadas a questões ambientais, visto que na cidade de Penedo o artesanato é confeccionado com diferentes materiais, mas a Taboa (Typha domingensis) se destaca, por exemplo, pela dureza e resistência. Atualmente, os artesãos encontram dificuldades para retirar a planta em seu habitat natural, devido ao avanço do agronegócio da canade-açúcar, que apesar de concentrar enorme fonte de recursos para o município traz impactos negativos ao ecossistema da região, como a desertificação e o empobrecimento do solo, a destruição da fauna e da flora, a extinção dos lenções freáticos e a exposição aos efeitos do uso de agrotóxicos.

De posse destas problemáticas, a perspectiva de trabalho acadêmico foi construída e aresentada ao Programa de Pós-Graduação em Ensino de Ciências e Matemática da Universidade Federal de Sergipe (PPGECIMA/UFS), com o objetivo de estudar as possibilidades e as limitações da inserção do artesanato, como tema social, para ensinar ciências/química.

A pesquisa, tornou-se relevante pelo fato de provocar a reflexão sobre algumas abordagens pouco trabalhadas no ciclo básico, mas que se contrapõem ao modelo de ensino tradicional-tecnicista-racionalista, de memorização de fórmulas e conteúdos, que remete a uma educação bancária (FREIRE,1997). E, a presença dos Flavonóides (isorramnetina e quercetina), com atividade anti-inflamatória, justificam a necessidade de se preservar a Taboa em seu habitat natural (CARVALHO, 2018), visto que a população ribeirinha faz uso da planta para tratar enfermidades.

\section{A contextualização}

A contextualização (CT) foi escolhida para facilitar a apresentação do tema e promover o ensino de ciências, já que se trata de uma abordagem bastante difundida na academia. Citamos, como exemplo: Lutfi $(1988,1992)$; Santos (2008, 2008); Santos; Mortimer (1999); Santos; Schnetzler (1996); Lopes (2002, 2010); Wartha; Faljoni-Alário (2005); Nascimento; Von Linsingen (2006); Lindemann (2009); Silva; Marcondes (2010); Coelho; Marques (2010); kato et al. (2011); Wartha; Silva; Bejarano (2013); Oliveira (2015); Solino; Gehlen 
(2016); Santos (2018). Porém, Santos (2008, p. 4) adverte que os professores, na maioria das vezes, somente exemplificam situações do cotidiano, pois:

[...] muitos professores consideram o princípio da contextualização como sinônimo de abordagem de situações do cotidiano, no sentido de descrever, nominalmente, o fenômeno com a linguagem científica. Essa abordagem é desenvolvida, em geral, sem explorar as dimensões sociais nas quais os fenômenos estão inseridos. Assim, se ensina nomes científicos de agentes infecciosos e processos de desenvolvimento das doenças, mas não se reflete sobre as condições sociais que determinam a existência de muitos desses agentes em determinadas comunidades.

Na tentativa de facilitar o trabalho dos professores com a CT, Santos e Mortimer (1999) defendem o ensino de ciências da natureza com ênfase nos contextos econômico, social, cultural e político, buscando a tomada de decisão. E, Santos e Schnetzler (1996) sugerem a formação cidadã utilizando a perspectiva da Ciência, Tecnologia e Sociedade (CTS), de forma interdisciplinar.

\section{A perspectiva Ciência, Tecnologia e Sociedade (CTS)}

Discussões e críticas ao modelo de desenvolvimento científicotecnológico adotado na maioria dos países, têm sido feitas utilizando-se as problemáticas da Ciência, da Tecnologia e da Sociedade (CTS), cujo objetivo principal é a alfabetização científica e tecnológica dos cidadãos, para auxiliar na construção de competências e habilidades que facilitem a autonomia de pensamento (ARAÚJO-QUEIROZ et al 2018). Contudo, a educação oferecida nas escolas brasileiras, em sua maioria, é feita de narrativas para estudantes que assistem passivamente a situações, muitas vezes, alheias a sua experiência diária. Este modelo de ensino, conhecido como "educação bancária, se multiplicou nas últimas décadas na escola pesquisada, apesar de ser um fenômeno nacional, e acaba por favorecer a alienação, a dominação dos sujeitos e exalta a condição do opressor sobre o oprimido. Freire (2001, p. 33) adverte:

[...] em lugar de comunicar-se, o educador faz "comunicados" e depósitos que os educandos, meras incidências, recebem pacientemente, memorizam e repetem. Eis aí a concepção 
"bancária" da educação, em que a única margem de ação que se oferece aos educandos é de receberem os depósitos, guardá-los e arquivá-los.

Em contraposição a concepção bancária de educação, Freire (2001) propõe a Educação Libertadora ou Educação Problematizadora (DE MORAIS COSTA; PINHEIRO, 2013), que estimula o aluno a sair da condição de ouvinte-passivo e buscar o diálogo, tendo a relação professor-alunoprofessor como horizontal e sustentada na motivação, no respeito ao saber/conhecimento do outro e na condição de ensinar e aprender. De acordo com Zavith et al. (2013, p. 275), existem concordâncias entre a visão freireana de educação e a proposta CTS:

[...] a ligação do referencial em Paulo Freire e da abordagem CTS ocorre por diversas maneiras, dentre elas as que relacionam conceitos de ambas as vertentes: a) palavras geradoras e investigação temática; b) educação política e participação pública; e c) educação problematizadora de Freire e a não-neutralidade da concepção de ciência.

É oportuno afirmar que a educação problematizadora de Freire, não combina com a neutralidade da ciência. Para Freire (2001, p. 21), não pode existir "prática educativa neutra, descomprometida, apolítica". E, a perspectiva CTS busca "desfazer $O$ mito do cientificismo que ideologicamente ajudou a consolidar a submissão da ciência aos interesses de mercado, à busca do lucro" (SANTOS; MORTIMER, 2002, p.6).

\section{O uso do Caso como perspectiva de ensino/aprendizagem}

O Caso (CS), que foi preparado para a pesquisa, é uma variação do método da Aprendizagem Baseada em Problemas (ABP), utilizado no Brasil pela Universidade Federal de São Carlos, no curso de Medicina. Diferentes pesquisadores (BRITO; SÁ, 2010; DA SILVA et al., 2011; SOUZA et al., 2012; PAZINATO; BRAIBANTE, 2014) já descreveram suas experiências com esta perspectiva, o que facilitou à adaptação para a unidade escolar. Segundo, Sá e Queiroz (2010, p. 731): 
[...] tão antigo quanto contar histórias, o uso de casos é a instrução pelo uso de narrativas sobre indivíduos enfrentando decisões ou dilemas. Na aplicação deste método o aluno é incentivado a se familiarizar com personagens e circunstâncias mencionados em um caso, de modo a compreender os fatos, valores e contextos nele presentes com o intuito de solucioná-lo.

método foi desenvolvido, para os alunos terem contato com problemas reais, estimulando habilidades como o pensamento crítico, a capacidade de resolução de problemas e a aprendizagem de conceitos relativos à uma área do conhecimento (SÁ; QUEIROZ, 2010).

O CS, utilizado na pesquisa, foi desenvolvido segundo a proposta de Sá e Queiroz (2010), para que o aprendiz tivesse a oportunidade de direcionar sua própria aprendizagem, investigando os aspectos sociais e científicos presentes em uma situação real, mas ao mesmo tempo simulada, de complexidade média e apresentando uma narrativa com alguns dilemas vividos por pessoas reais que precisam tomar decisões importantes, sobre determinadas questões.

\section{Caso: Salvem a Taboa em Penedo/Alagoas}

No corpo do texto, que remonta o CS, tivemos o cuidado de promover a colaboração entre a comunidade escolar e os moradores, para que juntos desenvolvessem uma campanha e buscassem uma solução para evitar a extinção da Taboa. Segue o texto divulgado para esta sensibilização:

\section{Salvem a Taboa em Penedo/Alagoas}

Lili, como é chamada pelos colegas de escola, é uma menina de olhos azuis e pele "branca" que lembra alguém com descendência europeia. As cores de seu rosto contrastam com a vegetação do lugar, que hora é cinza-amarronzada, na época seca, ou verde intenso das grandes plantações de cana de açúcar que sustentam as usinas de álcool da região.

A moça afirma que, atualmente, está cada vez mais difícil obter a folha da Taboa ou Typha domingensis, que é utilizada para confeccionar "objetos em palha", como bolsas, cestas e esteiras para dormir, entre outros. Conta, emocionada, que o artesanato em fibra vegetal, constitui uma atividade essencial na comunidade em que vive, pois contribui na complementação da renda das famílias, além de representar um conhecimento ou saber popular que foi transmitido de geração para geração, constituindo uma riqueza cultural que nem sempre é reconhecida pelos turistas ou pelos atravessadores.

A escassez do vegetal é atribuída a destruição do ecossistema característico da Caatinga, para prática da agricultura familiar ou da cana de açúcar, pecuária de gado leiteiro ou construção de moradias. 
Como forma de chamar a atenção da comunidade para o problema, Lili resolveu conversar com seus colegas de turma, para juntos buscarem uma alternativa. Após alguns impasses e propostas consideradas inviáveis, ela e seus colegas decidem ir pedir ajuda a professora Cláudia Regina, de ciências.

LILI: Bom dia professora, estamos precisando de sua ajuda para iniciarmos uma campanha sobre a preservação da Taboa em nossa comunidade, tem como a senhora auxiliar?

PROFESSORA: Claro que sim. O que acham de escrevermos, pequenos trechos informativos sobre a planta e divulgarmos na escola e depois no bairro. Estes textos podem ser científicos, poéticos ou descritivos. Podemos também criar um concurso de redação e desenhos sobre o problema com o tema: "Salvem a Taboa em Penedo". O que acham?

LILI: Massa, professora. Eu sabia, que a senhora era a pessoa certa para a campanha.

PROFESSORA: Então "tá", a parte pedagógica deixem comigo. E vocês tratam da divulgação e das conversas. Mão a obra. Vou enviar um e-mail, para uma amiga ambientalista pedindo ajuda.

Penedo, 06 de Nov. de 2018

Olá, querida amiga Marlene Rios Melo. A Taboa de nossa região está cada vez mais escassa, meus alunos precisam de ajuda para uma campanha de conscientização da comunidade escolar e de seu entorno, sobre a necessidade de preservar o ecossistema local. Gostaria que você nos ajudasse, para esta campanha. Bárbara, manda um abraço. Esperamos reencontra-la em breve.

Att., Prof (a). Cláudia Regina/SEED-AL.

Vocês são esses amigos da Lili, que junto com a professora Cláudia Regina terão que confeccionar pequenos trechos e ou desenhos que possam contribuir na realização da campanha: Salvem a Taboa em Penedo/Alagoas.

\section{Procedimentos metodológicos}

A pesquisa foi iniciada com um questionário, para levantamento da concepção dos estudantes sobre artesanato. A Análise de Conteúdo (AC), segundo defende Bardin (1977), foi utilizada para criar categorias e permitiu separar temas, palavras e ideias do texto e atribuir um peso relativo. A intervenção seguiu com o CS, para identificar o quanto a linguagem científica contribuiu para a formação da cidadania e a capacidade de tomada de decisão. Utilizamos sujeitos em formação, sendo necessário elaborar um Termo de Consentimento Livre e Esclarecido (TCLE). As abordagens utilizadas para encaminhar a pesquisa, tiveram como preocupação principal os contextos da escola, da comunidade e as ações de ensino/aprendizagem desenvolvidas pelo pesquisador ao longo do curso de mestrado, bem como de suas interações com as problemáticas da educação básica alagoana. 


\section{RESULTADOS E DISCUSSÃO}

Na primeira fase, os pesquisados foram identificados pela letra $\mathbf{A}$ e seguida de um número inteiro. O primeiro entrevistado, apresentou a representação $\mathbf{A} 1$, o segundo $\mathbf{A} 2$ e assim sucessivamente.

A primeira pergunta, que indagava sobre o entendimento dos alunos a respeito do artesanato, permitiu criar três categorias: 1. o artesanato confeccionado manualmente e a partir de recursos naturais; 2 . o artesanato como forma de expressão de uma cultura; e, 3. o artesanato manual e resultante da expressão de uma cultura.

Na categoria 1 (o artesanato confeccionado manualmente e a partir de recursos naturais), as respostas indicaram que há um pequeno entendimento dos sujeitos sobre o que seria artesanato, ou seja, uma atividade manual, com recursos retirados na natureza ou pela transformação de materiais. Verificar as respostas obtidas no quadro 1:

QUADRO 01: Respostas sobre o artesanato/categoria 1

\begin{tabular}{|c|c|}
\hline Sujeitos & Respostas Fornecidas \\
\hline A2 & $\begin{array}{l}\text {... é um trabalho manual feito de coisas simples que muitas vezes } \\
\text { achamos não ter serventia... }\end{array}$ \\
\hline A3 & ... artesanato são coisas feitas de barro ou materiais recicláveis... \\
\hline A5 & $\begin{array}{l}\text {... artesanato são objetos feitos a mão, com argila, madeira ou } \\
\text { outras coisas decoradas... }\end{array}$ \\
\hline A6 & ... artesanato é qualquer coisa feita de madeira, garrafas, barro... \\
\hline A7 & ... é um trabalho manual que utiliza matéria prima natural... \\
\hline A10 & $\begin{array}{l}\text {... artesanato é tudo que podemos criar com nossa criatividade, a } \\
\text { partir de recursos simples, como peças de barro, argila, madeira... }\end{array}$ \\
\hline A14 & $\begin{array}{l}\text {... artesanato é a arte de produzir objetos feitos manualmente e de } \\
\text { valor baixo, muitas vezes de materiais recicláveis... }\end{array}$ \\
\hline A16 & $\begin{array}{l}\text {... arte feita por pessoas chamados artesãos, que vem sendo } \\
\text { aprimorado ao longo do tempo conforme os costumes... }\end{array}$ \\
\hline A19 & $\begin{array}{l}\text {... é uma forma de arte que é feita com madeira, palha e barro } \\
\text { tudo isso pelas mãos do artesão... }\end{array}$ \\
\hline A20 & $\begin{array}{l}\text {... uma forma de arte bastante conhecida mas para alguns sem } \\
\text { valor. Usa matérias primas para fazer obras de arte e seu principal } \\
\text { instrumento de trabalho são suas próprias mãos. }\end{array}$ \\
\hline
\end{tabular}

Fonte: [o autor].

Observamos uma relação entre as respostas apresentadas pelos estudantes, que pode ser considerada uma visão simplista (de senso comum ou saber popular), com aquelas colhidas dos pesquisadores e utilizadas como referência do conhecimento científico. Alguns sujeitos percebem a 
dimensão cultural e popular da atividade, enquanto outros resumem a ideia de arte criativa e de expressão manual. Lima (2010) afirma que o artesanato é uma manifestação muito antiga, o que colabora com as descrições dos sujeitos A2, A5, A7, A14, A19 e A20:

[...] durante milênios foi o único modo que se tinha de fazer objetos. O mundo humano foi feito à mão. Se pensarmos no volume de objetos que já se produziu, manualmente, percebemos que é uma coisa impressionante e incalculável mesmo, porque acompanha o tempo da própria humanidade (LIMA, 2010, p.189).

As colocações de $\mathbf{A} 14, \mathbf{A} 10$ e $\mathbf{A} \mathbf{3}$ se completam e até parecem seguir uma ordem crescente de raciocínio e entendimento. Mas, a pouca disponibilidade de informações sobre a atividade artesanal na literatura brasileira (KELLER, 2014) impede que se faça uma análise mais aprofundada da contribuição no complemento da renda dos artesãos e de suas famílias.

[...] o trabalho artesanal é um fenômeno sociocultural e econômico presente na sociedade contemporânea. Uma atividade produtiva de valor social, cultural econômico exercida em geral de forma informal por grupos de produção espalhados por todo o Brasil e pela América Latina, grupos marcados por relações de família e de vizinhança, formados, em sua grande parte, por mulheres de baixa renda (KELLER, 2014, p. 326).

A informalidade da atividade e a característica de baixa remuneração (KELLER, 2014) destacam-se na interpretação do sujeito A20, que analisa o artesanato como "uma forma de arte bastante conhecida, mas para alguns sem valor". Para A14, o artesanato é a arte de produzir objetos feitos manualmente e de valor baixo.

Na categoria 2, com oito afirmações, o artesanato é visto como algo restrito a regiões rurais e de cidades históricas. Borges (2011) escreve que a forma de valorar o artesanato marginaliza a atividade, estimula a informalidade e impede a manutenção de ações de incentivo:

[...] desde 2001, órgãos do governo vem divulgando a existência de 8,5 milhões de artesãos no país, mas alertando que esse dado é impreciso, porque há um grande número de trabalhadores informais. Trata-se de uma atividade primordialmente feminina: calcula-se que $85 \%$ sejam mulheres. Muitas alternam a prática artesanal com outras ocupações, não considerando como sua principal atividade. Outras 
deixam de se cadastrar nos projetos governamentais de artesanato por medo de perder benefícios como Bolsa Família ou a aposentadoria, que no caso da agricultura familiar, impede o aposentado de ter outra profissão. Com medo de que alguém as denuncie, as artesãs omitem essa prática [...] (BORGES, 2011, p. 212).

A8, A13 e A17 não reconhecem que o artesanato esteja presente em regiões urbanas e fora do ambiente turístico. Assim sendo, devem ser preparadas intervenções para aprofundar a reflexão. Outra questão relevante, que também deve ser discutida, envolve a ideia sólida de que a cultura é algo acabado e imutável, escrita por A24 (“... é uma linda cultura que surgiu a vários anos atrás e utilizada até hoje...). Acreditamos ser necessário construir discursos mais legítimos e que desconsidere a hegemonia de definições, repassados por gerações e gerações como verdades absolutas. Neste sentido, Ferreira (1995, p. 94-95) afirma:

[...] é inegável que a cultura está sempre em transformação como coisa viva que é mas, pode-se afirmar que o atual processo de produção se modifica, gerando um grande dilema para o artesão: ele tem necessidade de modernizar seu produto para sobreviver mas, por outro lado, não pode perder seus traços identitários, pois é com isso que seu produto conta para ter acesso ao mercado do souvenir.

Nesse sentido, o Relatório de Economia Criativa da Conferência das Nações Unidas sobre Comércio e Desenvolvimento (UNCTAD, 2010, p. 140) classifica e define produto artesanal como:

[...] aqueles produzidos por artesãos sejam inteiramente à mão ou com a ajuda de ferramentas manuais, ou até por meio mecânicos, desde que a contribuição manual direta do artesão continue sendo o componente mais substancial do produto acabado. Definir e classificar artesanato é uma tarefa complexa. O artesanato tem características distintas e seus produtos podem ser utilitários, estéticos, artísticos, criativos, relacionados à cultura, decorativos, práticos, tradicionais, e de valor simbólico do ponto de vista religioso e social.

Defendemos 0 artesanato como algo criado pela inteligência do homem, oriundo de suas percepções e interações com o mundo, seja por saberes acumulados e ou compartilhados do grupo social. 
Na categoria 3 (junção de 1 e 2) os discursos foram incompletos ou incoerentes. A título de ilustração, destacamos dois deles. Para A15, "o artesanato está presente em qualquer cidade", o que nos leva a concluir que, como não há precisão nos dados oficiais é questionável qualquer análise mais consistente. Quanto ao sujeito A9, este afirma que o artesanato "demonstra um pouco da cultura da região de onde é feito, sendo algo que identifica um povo", o que se aproxima dos estudos De Sousa Santos et al. (2010, p.8):

[...] é a cultura que distingue a identidade de um indivíduo e possibilita identificá-lo como membro de uma sociedade. Detentor de uma série de conhecimentos, hábitos e valores adquiridos por seus semelhantes, este indivíduo reconhece outros membros de seu grupo, interage com os mesmos e com outras comunidades, transmite às gerações futuras sua cultura e preserva particularidades de seu povo[...].

A4, descreve o artesanato como "forma de expressar arte através de escultura, imagens, tecidos". Esta visão, pouco abrangente, desperta à reflexão sobre a importância de combater um ensino racionalista, que insiste na repetição de palavras e frases em detrimento da construção do conhecimento, que Freire $(2005$, p.123) indicou como sendo: "o desrespeito à leitura de mundo do educando revela o gosto elitista, portanto antidemocrático". E, Brasil (1999, p. 07) esclarece:

[...] conhecer e valorizar a pluralidade do patrimônio sociocultural brasileiro, bem como aspectos socioculturais de outros povos e nações, posicionando-se contra qualquer discriminação baseada em diferenças culturais, de classe social, de crenças, de sexo, de etnia ou outras características individuais e sociais [...].

A questão social, que esteve presente durante toda a pesquisa e caracterizou as relações interpessoais na escola, influenciou na participação dos estudantes na segunda fase. A proximidade do fim do ano letivo e a incerteza do transporte escolar, culminaram na baixa frequência e consequentemente, no volume menor de participações. Contudo, 28 questionários foram preenchidos, sendo que 15 contribuíram efetivamente, 
para a análise; 8 (oito) tiveram partes em branco; 5 (cinco) incluíram repetições de trechos do texto ou com escrita fora da problemática.

As respostas com partes do texto desconectados, e com erros gramaticais, resumem o vício que acompanha alguns alunos, ou seja, transcrever a "fala" do professor como algo imutável, sem questionar ou refletir sobre o que escreveu. De acordo com Chassot (1993, p. 57), o ensino deve acompanhar "Três Interrogantes Capitais": por que ensinar?; o que

\section{ensinar?; como ensinar?}

O por que ensinar, propõe facilitar a leitura do mundo. Com isso, os aspectos sociais, culturais e econômicos que se apresentam junto a questão do artesanato, bem como a dificuldade cada vez maior em obter a Taboa, no seu ambiente natural, em virtude da degradação do ecossistema da região, justifica a conexão desta pesquisa com a interrogação inicial feita por Chassot (1993, p. 40), que acrescenta:

[...] poder-se-ia perguntar mais: o ensino de Química, tal como é feito, é útil para quem? Não será ele também coresponsável pelo aumento das diferenças entre classes? Enquanto as classes dominadas receberem um ensino livresco, haverá menos oportunidades para diminuir as diferenças de classes.

A concepção de Chassot (1993) corrobora com Freire (1987) ao destacar a necessidade de romper com o ensino simplista e tradicional, de concepção bancária, para uma nova proposta onde o professor atue como orientador e provoque discussões e reflexões no educando sobre a sua condição submissa. Outra posição importante a ser destacada envolve a questão cultural que Freire (1987) promoveu ao questionar o que é considerado saber popular e saber erudito. Durante nossa pesquisa, defendemos a visão de que não existe saber/conhecimento constituído como certo ou errado, mas sim aqueles trazidos de um contexto sóciocultural que agrega e inserem as minorias. Conforme Sodré (1990), o indivíduo isolado oferece uma interpretação parcial dos fatos, daí a necessidade de combater a imparcialidade para não aparentar existir uma 
única verdade e um padrão incontestável. Neste sentido, Freire (1987, p. 86) esclarece:

[...] como evitar a dicotomia entre esses saberes, o popular e o erudito ou o de como compreender e experimentar a dialética entre o que Snyders chama 'cultura primeira' e 'cultura elaborada'" e que, "o respeito a esses saberes se insere no horizonte maior em que eles se geram - o horizonte do contexto cultural, que não pode ser entendido fora do seu corte de classe [...] O respeito, então, ao saber popular implica necessariamente 0 respeito ao contexto cultural.

Chassot (1993), adverte sobre o que ensinar e para quem ensinar, sobre a ótica da formação de um cidadão mais participativo nas decisões de sua comunidade, o que é consonante com o que Freire (2011) combateu, por exemplo, em Pedagogia do Oprimido (2011).

A consciência que o oprimido possui, na maioria das vezes, foi moldada pela concepção de mundo que o opressor desenhou para ele, assim, o oprimido absorve os valores e às ideologias que lhe são permitidas, tendo uma falsa consciência e de acordo com os interesses do opressor. $\bigcirc$ modelo de educação libertadora, defendida por Freire (2011) e corroborado por Chassot (1993), provoca a reflexão do cidadão:

[...] mesmo que o professor tenha dificuldades em selecionar assuntos mais ligados ao cotidiano e venha a preferir os "conteúdos clássicos" (aqueles que se disse que são universalmente ensinados), por encontrar nisso apoio nos livros-texto. É preciso questionar de maneira enfática: o que ensinar sobre determinado assunto? É preciso que se tenha uma adequação para cada etapa da escolarização. Isto significa, por exemplo, que modelos mais simples podem explicar mais convenientemente certos assuntos que modelos mais sofisticados. É importante ressaltar que mais simples não significa, necessariamente, menos correto, ou até incorreto (CHASSOT, 1993, p.43).

A questão de como ensinar esbarra na formação do professor. Esperase a postura de um educador crítico que não negue as diferenças, trabalhe para diminuir as desigualdades e busque romper com a relação autoritária do conhecimento/saber padronizado e hegemônico. Neste sentido, a pergunta 1, do estudo de caso, solicita ao aluno que explique, em um parágrafo, o principal assunto abordado. Consideramos que estimular a 
escrita e a reflexão de situações, que os estudantes vivenciam no cotidiano é importante para exercitar a prática cidadã.

As respostas foram numeradas de 1 a 15 e identificadas pela letra "S" maiúscula, para a abreviação da palavra "sujeito". Alguns pesquisados, como S1, S3, S4, S5, S9 e S15, apresentaram maior consistência do retorno ao que foi proposto. Mesmo parecendo ter ocorrido uma espécie de "cópia fiel", de partes do parágrafo, existiu uma conexão explícita entre pergunta e resposta.

Acreditamos que a falta de profundidade sobre o que se escreve é um problema grave na formação dos alunos. Talvez, oriunda do tipo de ensino oferecido e que não trabalha a argumentação, sejam em situações simples do dia a dia da sala de aula ou aquelas ditas mais profundas e que envolvem discussões sobre temas CTS, por exemplo. No quadro 02, a seguir, encontram-se ilustradas as respostas que tiveram maior conexão e argumentação, com base no marco teórico assumido neste estudo:

QUADRO 02: Respostas mais consistentes sobre a pergunta número 1

\begin{tabular}{|c|c|}
\hline Sujeitos & $\begin{array}{l}\text { Respostas Fornecidas/pergunta número 1: explique, em um } \\
\text { parágrafo, o principal assunto abordado no caso descrito }\end{array}$ \\
\hline S1 & $\begin{array}{l}\text {... apresenta a dificuldade da obtenção da folha da taboa e que } \\
\text { sua escassez esta atribuída a destruição do ecossistema } \\
\text { (caatinga)... }\end{array}$ \\
\hline S3 & $\begin{array}{l}\text {... o texto aborda uma folha chamada Taboa que no momento } \\
\text { encontra em extinção... }\end{array}$ \\
\hline S4 & $\begin{array}{l}\text {... está sendo abordado a escassez do vegetal, que "atribui" a } \\
\text { distribuição do ecossistema... }\end{array}$ \\
\hline S5 & $\begin{array}{l}\text {... O assunto que está sendo abordado é a escassez do vegetal, } \\
\text { que atribui a destruição do ecossistema... }\end{array}$ \\
\hline S9 & $\begin{array}{l}\text {... é possível afirmar que o texto reflete como principal, a escassez } \\
\text { da folha da Taboa, aliado a problemas ambientais causados pela } \\
\text { população urbana... }\end{array}$ \\
\hline$S 15$ & $\begin{array}{l}\text {... a dificuldade da obtenção da folha de Taboa usada para } \\
\text { objetos em palha como: bolsas, cestos e esteiras. Além de } \\
\text { contribuir para a renda das famillias da comunidade. Mas, } \\
\text { infelizmente essa folha está em extinção... }\end{array}$ \\
\hline
\end{tabular}

Fonte: [o autor].

Estudos anteriores, como por exemplo Mendonça (2013); Sasseron (2015); Villani; Do Nascimento (2016); Ferraz e Sasseron (2017), destacam a necessidade de promover nas aulas de ciências uma espécie de "qualificação" da argumentação em discussões de aspectos sócio- 
científicos. No entanto, na forma que é apresentada, sem exercitar o debate e tendo o livro didático como parâmetro, por exemplo, não estimula o diálogo, não propõe questionamentos e nem cria oportunidades para argumentações. Sá e Queiroz (2010, p. 02), afirmam que a argumentação:

[...] é uma atividade social, intelectual e verbal, utilizada para justificar ou refutar uma opinião e que consiste em fazer declarações, levando em consideração o receptor e a finalidade com a qual se emitem. Para argumentar é necessário escolher entre diferentes opções ou explicações e raciocinar sobre os critérios que permitam avaliar como mais adequada a opção escolhida.

Apesar do pequeno espaço destinado a prática argumentativa nas atividades desenvolvidas na escola pesquisada, constatamos que os sujeitos S2, S6, S7, S10, $\$ 11$ e $\mathbf{S 1 2}$ tiveram capacidade para entender e resumir a problemática do texto. O quadro 03, a seguir, indica estas percepções.

QUADRO 03: Respostas sobre a pergunta número 1

\begin{tabular}{|c|c|}
\hline Sujeitos & $\begin{array}{l}\text { Respostas Fornecidas/pergunta número } 1: \text { explique, em um } \\
\text { parágrafo, o principal assunto abordado no caso descrito }\end{array}$ \\
\hline S2 & $\begin{array}{l}\text {... a escassez da Taboa em Penedo/Alagoas, por matéria prima } \\
\text { para a comunidade, onde é usada para "renda família", } \\
\text { confecção de objetos artesanais "feito" na comunidade }\end{array}$ \\
\hline 56 & $\begin{array}{l}\text {... o assunto "fala" de uma planta em que a sua folha da Taboa } \\
\text { não está sendo preservada e com isso fica muito difícil obter a } \\
\text { folha para confeccionar as bolsas, cestos e as esteiras de palaha... }\end{array}$ \\
\hline S7 & $\begin{array}{l}\text {... a falta da Taboa na região de Penedo e como podemos } \\
\text { preservá-la }\end{array}$ \\
\hline S10 & $\begin{array}{l}\text {... atualmente está cada vez mais difícil obter a "folha de Taboa ou } \\
\text { Typha domingensis", que é utilizada para confeccionar "objetos e } \\
\text { palhas", como bolsas, cestas e esteiras piçara dormir }\end{array}$ \\
\hline s11 & $\begin{array}{l}\text {... ajudar a salvar a Taboa em Penedo/Alagoas, "para preservar } \\
\text { mas esta campanha, pedem ajudar, fazendo divulgações, } \\
\text { comentários e distribuindo panfletos }\end{array}$ \\
\hline 2 & $\begin{array}{l}\text {... o principal assunto abordado é a falta da folha da Taboa, onde } \\
\text { se encontra mais difícil o caso do cultivo e do "plantio" da folha }\end{array}$ \\
\hline
\end{tabular}

Fonte: [o autor].

As contribuições dos sujeitos $\mathbf{S 5}$ e $\mathbf{S 8 ,} \mathbf{S 1 3}$ e $\mathbf{S 1 4}$, ilustradas no quadro 04, na página seguinte, acabaram por ser repetições de ideias, porém, não foram desconsideradas e consolidam a visão da necessidade de praticar um ensino de ciências, na educação básica, que esteja centrado nos aspectos 
sócio-científicos e favoreça o exercício da cidadania (SANTOS; SCHNETZLER, 1996).

QUADRO 04: Respostas sobre a pergunta número 1

\begin{tabular}{|c|c|}
\hline Sujeitos & $\begin{array}{l}\text { Respostas Fornecidas/pergunta número } 1 \text { explique, em um } \\
\text { parágrafo, o principal assunto abordado no caso descrito }\end{array}$ \\
\hline S5 & $\begin{array}{l}\text { o assunto abordado é a escassez do vegetal que é causado } \\
\text { ela destruição do ecossistema... }\end{array}$ \\
\hline S8 & cassez do vegetal que é causado \\
\hline$S$ & $\begin{array}{l}\text {... a moça afirma que atualmente está cada vez mais difícil de } \\
\text { obter a folha da Taboa ou Typha domingensis... }\end{array}$ \\
\hline 14 & $\begin{array}{l}. \text { a moça afirma que atualmente está cada vez mais di } \\
\text { olha }\end{array}$ \\
\hline
\end{tabular}

Fonte: [o autor].

As problemáticas sócio-científicas devem estar presentes nos currículos, para estimular o pensamento crítico, a prática cidadã e a tomada de decisão dos estudantes. Sendo assim, os professores devem privilegiar em seus planejamentos problemas sociais, crises ambientais, poluição, crise energética, movimentos sociais e estudantis, além das lutas anti-segregação racial, por exemplo, uma vez que são temas sociais do mundo globalizado.

A pergunta 2 foi inserida para que os alunos descrevessem como o problema abordado no texto se vinculava a questões sociais, econômicas, ambientais e éticas. A citação da problemática, que envolve o cultivo da cana-de-açúcar, associado a destruição do bioma da Caatinga, exalta a questão CTS na pesquisa. Na cidade de Penedo/AL o cultivo da cana é destinado as usinas de açúcar e álcool, que na tentativa de reduzirem o custo operacional, para ter um produto final competitivo no mercado, se utilizam da queimada com o objetivo de facilitar as operações de colheita, mesmo havendo leis que regulamentam a atividade que é nociva ao meio ambiente.

Na cidade de Penedo e suas redondezas, que englobam outros municípios, como Igreja Nova e Coruripe, a agroindústria da cana-deaçúcar constitui-se num negócio lucrativo para os usineiros, mas também é responsável por impactar a vida de diversas famílias que residem nestas localidades, com graves efeitos sociais (sazonalidade da produção gerando 
desemprego); ambientais (queima da palhada da cana com formação de material particulado); éticos (destruição do ecossistema e falta de fiscalização do órgãos públicos); econômicos (formação de mão-de-obra barata e não especializada).

A pergunta 3, convoca para o julgamento sobre a gravidade do problema apresentado, também com uso de justificativa de resposta. Observamos que a aplicação de atividades que envolvem leitura e interpretação de texto podem ser alternativas ao ensino construído pela memorização. O que foi indicado por $\mathbf{5 9}$, ao mencionar a ajuda do governo para evitar a sua extinção: "De acordo com a gravidade da situação é possível afirmar que é um problema ambiental... (...) ○ instituto de meio ambiente poderia criar um projeto de "plantação" da Taboa para evitar a extinção."

O sujeito $\mathbf{S 1 2}$ reconhece que a cidade precisa de empresas e indústrias para se desenvolver, mas é preciso avaliar locais para o cultivo da Taboa, no intuito de preservá-la: "A cidade por sua vez necessita de empresas... (...) a falta do plantio da Taboa prejudicará diversos familiares e ao artesanato da cidade onde são bastante procurados por visitantes".

Apesar das respostas apresentadas pelos sujeitos $\mathbf{S 9}$ e $\mathbf{\$ 1 2}$ convergirem para uma ideia de preservação da Taboa, a forma escolhida como alternativa não é razoável. Delegar ao governo ou ao agronegócio, a responsabilidade de preservação do meio ambiente não me parece muito coerente. As leis são frágeis e os governantes corruptos e corruptores, mas reconhecemos um avanço no pensar destes sujeitos em relação ao grupo pesquisado. Talvez a forma de estruturação do ensino médio, com disciplinas desconectadas e que pouco levam o aprendiz a reflexão, possa implicar nesta maneira de agir: delegar ao poder público a responsabilidade de preservar os ecossistemas.

A educação que defendemos, de forma geral, envolve a participação de professores e alunos, que através da interação com o cotidiano em que vivem, apreendem e extraem os conteúdos necessários para atingirem a percepção da consciência de sua realidade, no sentido de atuarem para 
uma transformação social. Então, nossa visão converge para uma "educação libertadora" que, ao contrário da "bancária", questiona as relações do homem com a natureza e com os outros homens.

O uso de "temas sociais", que são extraídos da problematização da vida cotidiana, descreve a experiência vivida no cotidiano para uma atitude crítica. Segundo Freire (1987, p. 61):

[...] a criticidade para nós implica na apropriação crescente de sua posição no contexto. Implica na sua inserção, na sua integração, na representação objetiva da realidade. Daí a conscientização ser o desenvolvimento da tomada de consciência. Não será, por isso mesmo, algo apenas resultante das modificações econômicas, por grandes e importantes que sejam. A criticidade, como entendemos, há de resultar de um trabalho pedagógico crítico, apoiando em condições históricas propícias.

Na obra de Paulo Freire, a busca pela necessidade de conscientizar educadores e educandos é constante. Segundo o autor, "ninguém educa ninguém, pois os homens aprendem comunitariamente" (FREIRE, 1997, p.68). Então, à medida que os saberes são trocados e transferidos de um ser para outro é construído de forma conjunta, um novo saber e é esse processo que favorece a autonomia do educando.

O sujeito $\$ 15$ destacou a questão cultural que envolve a Taboa e alerta que a sua escassez na região está relacionada ao não reconhecimento pelos turistas da riqueza cultural que envolve os objetos confeccionados:

\footnotetext{
"essa folha é uma riqueza cultural que nem sempre é reconhecida pelos turistas e pelos atravessadores, talvez seja por isso que a folha está sendo ameaçada. Além da destruição do sistema".
}

Com relação ao S15, sua resposta envolve duas questões relevantes em sua resposta: a "destruição do sistema" (ecossistema) e a questão cultural. A expansão da cultura da cana-de-açúcar, ao longo dos séculos, deixou como herança negativa o avanço da fronteira agrícola sobre áreas naturais, principalmente, no bioma da Mata Atlântica. Segundo Ronquim (2010, p. 20): 
[...] a queima da cana emite certas quantidades de compostos nitrogenados com atividade química e biológica e tem potencial para modificar as propriedades físicas do ambiente ou da biota. 0 nitrogênio ativo ( $\mathrm{NO}$ e $\mathrm{NO}_{2}$ ) é responsável por provocar problemas ambientais locais e regionais, como a chuva ácida e a contaminação de águas, e ainda tem grande potencial para afetar a biodiversidade de florestas naturais. [...] nos ambientes aquáticos, o efeito é imediato, com o crescimento exacerbado da população de algas (eutrofização), que libera toxinas e consome quase todo o oxigênio da água. O dióxido de nitrogênio $\left(\mathrm{NO}_{2}\right)$ presente na atmosfera é transformado em ácido nítrico e forma a chuva ácida, que modifica $\circ \mathrm{pH}$ do solo e das águas. $\mathrm{O} \mathrm{N}_{2} \mathrm{O}$ tem também a propriedade de catalisar reações atmosféricas em presença de luz solar, as quais formam, entre outros gases, o ozônio.

Atualmente, o uso intensivo de agrotóxicos, por exemplo, representa um fator que contribui para à eutrofização dos rios e lagos, à acidificação dos solos e à contaminação de aquíferos.

A segunda parte da análise da resposta de \$15, que afirma sobre turistas e atravessadores que não valorizaram a produção artesanal da fibra da Taboa, pode ser refletida por aspectos do interculturalismo. A questão cultural, que já discutimos, envolve a "quebra" de um padrão hegemônico que precisa ser combatido, mas que o ensino tradicional é insuficiente para fomentar essa mudança.

A educação, oferecida na maioria das escolas brasileiras, não é neutra e serve aos interesses da classe dominante. Isto se evidencia quando, de modo desigual, se escolhe os conteúdos de ensino, com o objetivo de manter o ideário e a lógica de pensar do sistema capitalista, ao excluir as problemáticas culturais dos saberes regionais.

A questão epistemológica da legitimação social do saber popular que é, historicamente, desvalorizado em detrimento do saber científico, se reveste de caráter opressor na sociedade pós-moderna, constituindo-se num elemento de diferenciação de classe social, onde a cultura dominante e de "saber real" "sufoca" a cultura dominada do "não-saber". De acordo, Chauí (1990, p. 51) é uma:

[...] forma nova e sutil de reafirmar que a barbárie se encontra no povo na dimensão da 'incultura' e da 'ignorância', imagem preciosa para o dominante sob dois aspectos: de um lado, a suposta universalidade do saber dá-Ihe neutralidade e disfarça seu caráter 
opressor; de outro lado, a 'ignorância' do povo serve para justificar a necessidade de dirigi-lo do alto e, sobretudo, para identificar a possível consciência da dominação com o irracional, visto que lutar contra ela seria lutar contra a verdade (o racional) fornecida pelo conhecimento.

A cultura é um produto da existência do ser humano e de seu processo de humanização, como também da sua relação com a natureza que cria formas de ser e de viver distintas. Portanto, a visão de saber da classe dominante legítima a reflexão proposta por Chassot (1993), do que ensinar, para que ensinar e como ensinar.

A pergunta de número 4, com respostas agrupadas no quadro 05 , abaixo, induz os sujeitos a opinarem sobre as medidas que poderiam ser tomadas para resolver a situação apresentada no Caso.

QUADRO 05: Respostas Fornecidas/pergunta número 4

\begin{tabular}{|c|c|}
\hline Sujeitos & Respostas Fornecidas/pergunta número 4 \\
\hline S1 e S2 & $\begin{array}{l}\ldots \text { que sugeriram o uso de outras plantas para produzir o } \\
\text { artesanato em fibra vegetal e a preservação do ecossistema; }\end{array}$ \\
\hline S3 & $\begin{array}{l}\text {... que utilizaria os recursos da mídia para conscientizar as pessoas } \\
\text { sobre a preservação da Taboa; }\end{array}$ \\
\hline S6 & $\begin{array}{l}\text {... que acrescenta a necessidade de plantar o dobro de plantas } \\
\text { retiradas; }\end{array}$ \\
\hline S7 & $\begin{array}{l}\text { manter as pessoas informadas sobre a importância da } \\
\text { omo forma de incentivar a preservação; }\end{array}$ \\
\hline \$8 & so, no intuito de evitar a extinção; \\
\hline$S 10$ & $\begin{array}{l}\text {... solicita ajuda governamental, para aqueles que sobrevivem do } \\
\text { artesanato; }\end{array}$ \\
\hline S11 & $\begin{array}{l}\text {... promover ações para que a comunidade obtenha mais } \\
\text { informações, sobre a Taboa na cidade de Penedo; }\end{array}$ \\
\hline$S 12$ & $\begin{array}{l}\text {... sugere medidas de conservação e de cultivo, visando a } \\
\text { preservação; }\end{array}$ \\
\hline$\$ 13$ & $\begin{array}{l}\text {... explica que se o governo oferecesse emprego para os } \\
\text { trabalhadores, não haveria necessidade de usar a folha da Taboa } \\
\text { como "forma de ganhar o pão"; }\end{array}$ \\
\hline$S 14$ & $\begin{array}{l}\text {... sugere que a população se uma, no sentido de preservar o } \\
\text { ecossistema; }\end{array}$ \\
\hline$\$ 15$ & $\begin{array}{l}\text {... acrescenta que as medidas essenciais para esse problema seria } \\
\text { fazer com que essa "folha" ficasse bem conhecida, para que a } \\
\text { comunidade visse a sua importância; }\end{array}$ \\
\hline
\end{tabular}

Fonte: [o autor].

S3, S7 e S15 sugerem ações que busquem informar à comunidade sobre a importância de se preservar a Taboa, e \$14 destaca a união das pessoas para à preservação. Já $\mathbf{S 1 3}$, transfere para o governo a responsabilidade da 
falta de emprego, como sendo a razão para que as pessoas utilizem a atividade artesanal para gerar renda. Esta visão simplista e de certa forma preconceituosa, é um indicativo da ausência de ações que destaquem aspectos interculturais do artesanato na escola. E, S8 sugeri o controle no uso da planta, apesar do texto citar a destruição do meio ambiente para atividades de pecuária, agricultura familiar, construção de moradias e cultivo de cana-de-açúcar como fatores responsáveis pela dificuldade em encontrar a Taboa em seu ambiente natural.

A pergunta 5 provoca o leitor a citar, dentre as medidas relatadas por ele no item anterior, qual alternativa seria mais viável para promover a solução do Caso. Muitos repetiram o que haviam escrito no item 4, sendo que alguns com mais argumentos e outros de forma superficial. Talvez a aplicação de outros Casos ou o uso de atividades que possibilitassem a leitura e a interpretação de textos, promovessem um maior conhecimento das potencialidades da Taboa. A partir do melhor entendimento, os alunos ao se motivarem poderiam criar saídas mais expressivas para resolver o Caso.

\section{CONSIDERAÇÕES FINAIS}

O Caso, no contexto do Ensino de Ciências/Química, não é muito utilizado e há poucas publicações na área, o que constitui uma alternativa ao ensino tradicional-tecnicista-racionalista praticado na maioria das escolas e que não leva o aluno a pensar e criar alternativas para a realidade que vive, mas somente o impulsiona a reproduzir o que "aprendeu".

A aplicação do Caso "Salvem a Taboa em Penedo/Alagoas" permitiu concluir que:

- os alunos, apesar de lerem o texto só interpretam superficialmente, o que os torna incapazes, na maioria das vezes, de propor alternativas;

- o ensino tradicional, de memorização de fórmulas e conteúdos, impossibilita ao aluno construir textos reflexivos, já que algumas respostas, analisados neste estudo, tiveram repetição total ou parcial, dos fragmentos do texto; 
- as questões propostas, que envolveram os aspectos sociais e éticos não tiveram respostas consistentes o que atribuímos a dois fatores principais: ausência de professor, com formação na área de filosofia ou sociologia e não utilização de atividades que envolvem a questão ética na escola;

- a formação do professor, que o impede de criar novas alternativas de ensino e aprendizagem;

- a mudança de paradigmas pelos professores, que resistem em não construir novas perspectivas de ensino/aprendizagem.

$O$ estudo do artesanato e sua relação com o ensino de ciências possibilitou trabalhar com questões que levam a valorização da cultura local, que muitas vezes é "sufocada" por um padrão que é imposto pela classe dominante. Portanto, a construção de atividades que exaltam a riqueza local e valorizam os saberes/conhecimentos de comunidades tradicionais, devem fazer parte do planejamento curricular. Acreditamos que a resistência dos docentes em criar formas de trabalhar os conteúdos, depende de sua motivação e da sua formação o que pode ser explorado em outros estudos.

Acreditamos que, para as alunas/alunos atuarem como cidadãos seja necessário a reflexão sobre os aspectos sociais, ambientais, éticos e econômicos. Portanto, exercitar a reflexão e a argumentação para, por exemplo, perceber a necessidade de preservar a Taboa, que não é só importante para o artesanato, mas que comprovadamente, possui propriedades medicinais, terapêuticas e de biorremediação.

Com o desenvolvimento da pesquisa, esperava-se que os alunos percebessem alguma relação entre a destruição do ecossistema e a visão de costumes, virtudes e moral trabalhadas nos aspectos filosófico e ou sociológico. Para fundamentar a discussão, trouxemos Hans Jonas e a crítica a filosofia "Kantiana". Nesse sentido, podemos construir um estudo interdisciplinar que envolva o artesanato e suas implicações sociais, ambientais, éticas e tecnológicas.

A perspectiva de novos trabalhos, que envolve a questão ambiental, deve ser construída no âmbito da agricultura familiar ou das práticas de 
cultivo e adubação, como por exemplo, a compostagem de resíduos sólidos orgânicos. Nesse sentido, a preocupação com o uso de defensivos agrícolas durante o ciclo da cana-de-açúcar, com discussões sobre a contaminação dos mananciais de água é oportuno e pode ser um caminho para inserir no cotidiano escolar questões sobre a preservação da bacia do Rio São Francisco, que tanto sofre com o desmatamento em suas margens e 0 esgoto clandestino.

\section{REFERÊNCIAS}

ARAÚJO-QUEIROZ, M. B.; DA LUZ SILVA, R.; PRUDÊNCIO, C. A. V. Estudos CTS na educação científica: tendências e perspectivas da produção stricto sensu no Nordeste brasileiro. Revista Exitus, v. 8, n. 3, p. 310-339, 2018.

BARDIN, L. Content analysis. São Paulo: Livraria Martins Fontes, 1977.

BAROLLI, E.; VILLANI, A. A formação de professores de Ciências no Brasil como campo de disputas. Revista Exitus, v. 5, n. 1, p. 72-90, 2016.

BEDIN, E.; DEL PINO, J. C. Da discência à docência: concepções e perspectivas na formação inicial de professores de química sobre a Sequência Didática-SD. Revista Exitus, v. 9, n. 1, p. 119-147, 2019.

BORGES, A. Design + Artesanato: o caminho brasileiro. São Paulo: Terceiro Nome, 2011.

BRASIL. Ministério da Educação (MEC), Secretaria de Educação Média e Tecnológica (Semtec). Parâmetros Curriculares Nacionais para o Ensino Médio. Brasilia: MEC/Semtec, 1999.

BRITO, J. Q. A.; SÁ, L. P. Estratégias promotoras da argumentação sobre questões sócio-científicas com alunos do ensino médio. Revista electrónica de enseñanza de las ciências, v. 9, n. 3, p. 505-529, 2010.

CACHAPUZ, A., GIL-PÉREZ, D., CARVALHO, A.M.P., PRAIA, J. e VILCHES, A. (orgs). A Necessária Renovação do Ensino de Ciências, São Paulo, Cortez, 2005.

CARVALHO, A. F. de. Mulheres artesãs: extrativismo da taboa (Typha spp.) em Pacatuba/SE. 2018. 230 f. Tese (Doutorado em Desenvolvimento e Meio Ambiente) - Universidade Federal de Sergipe, São Cristóvão, SE, 2018.

CHASSOT, A. I. Catalisando transformaçōes na educação. Ijuí: Editora Unijuí, 1993. 
CHAUÍ, M. O que é ideologia. São Paulo: Brasiliense, 1980. (Coleção primeiros Passos).

COELHO, J. C.; MARQUES, C. A. Contribuições freireanas para a contextualização no ensino de Química. Ensaio Pesquisa em Educação em Ciências, v. 9, n. 1, p. 1-17, 2010.

CORTES, M. R. et al. Mulher na ciência:" Ciência também é coisa de mulher". Niterói. 2017. 127 f. Trabalho de Conclusão de Curso (Graduação em Física) Universidade Federal Fluminense, Instituto de Física, Niterói, RJ, 2017.

DA SILVA, J. R. Contextualização, Experimentação e a Pesquisa na Web para Despertar o Interesse pelo Estudo das Reações Químicas. Scientia Plena, v. 12, n. 11, 2016.

DA SILVA, O. B.; DE OLIVEIRA, J. R. S.; QUEIROZ, S. L. SOS Mogi-GuaçU: contribuições de um Estudo de Caso para a educação química no nível médio. Química Nova na Escola, v. 33, n. 3, ag. 2011.

DE CARVALHO, A. M. P. A necessária renovação do ensino de Ciências. São Paulo: Cortez Editora, 2005.

DE CARVALHO, A. M. P; GIL-PÉREZ, D. Formação de professores de ciências. São Paulo, Cortes Editora, 2006.

DE CARVALHO, A. M. P.; GONÇALVES, M. E. R. Formação continuada de professores: o vídeo como tecnologia facilitadora da reflexão. Cadernos de Pesquisa, n. 111, p. 71-94, 2013.

DE MORAIS COSTA, J.; PINHEIRO, N. A. M. O ensino por meio de temasgeradores: a educação pensada de forma contextualizada, problematizada e interdisciplinar. Imagens da Educação, v. 3, n. 2, p. 37-44, 2013.

DE SANT'ANA, J. V. B.; SUANNO, J. H.; DE CASTRO, R. M. M. Afrocentricidade e interculturalidade crítica na educação: reinventar a escola a partir da diferença. Revista Exitus, v. 9, n. 1, p. 426-454, 2019.

SANTOS, T. D. S.; NASCIMENTO, J. P. D. B.; BORGES, G. D. F.; MORAES, A. F. D. O.; TEIXEIRA, E. (2010). O artesanato como elemento impulsionador no desenvolvimento local. Anais do VII Simpósio de Excelência de Gestão e Tecnologia.

DEMO, P. Cidadania tutelada e cidadania assistida. Campinas: Autores Associados, 1995.

DEMO, P. Política social, educação e cidadania. 10. ed. Campinas: Papirus, 2007. 
FERRAZ, A. T.; SASSERON, L. H. Propósitos Epistêmicos para a promoção da argumentação em aulas investigativas. Investigações em Ensino de Ciências, v. 22, n. 1, 2017.

FERREIRA, M. N. Considerações acerca da cultura subalterna como mercadoria. In: Globalização e identidade cultural na América Latina. São Paulo: CELACC, 1995.

FREIRE, P. Educação "bancária" e educação libertadora. Introdução à psicologia escolar, v. 3, 1997.

FREIRE, P. Pedagogia da Autonomia: Saberes Necessários à Prática Educativa; 4a. ed., São Paulo: Paz e Terra, 2001.

FREIRE, P. Conscientização, teoria e prática da libertação: uma introdução ao pensamento de Paulo Freire. São Paulo: Editora Centauro, 2005.

FREIRE, P. Pedagogia do Oprimido. 50a. ed., Rio de Janeiro: Paz e Terra, 2011.

FREIRE, P.; SHOR, I. Medo e ousadia: o cotidiano do professor. Rio de Janeiro: Paz e Terra, 1987.

GATTI, B. A. Formação de professores: condições e problemas atuais. Revista internacional de formação de professores, v. 1, n. 2, p. 161-171, 2016.

GEHLEN, S. T.; DELIZOICOV, D. A dimensão epistemológica da noção de problema na obra de Vygotsky: implicações no ensino de ciências.

Investigações em Ensino de Ciências, v. 17, n. 1, p. 59-79, 2016.

GUIMARÃES, L. P. et al. Ensino de Ciências e experimentação: reconhecendo obstáculos e possibilidades das atividades investigativas em uma formação continuada. Revista Thema, v. 15, n. 3, p. 1164-1174, 2018.

KATO, D. S. et al. As concepções de contextualização do ensino em documentos curriculares oficiais e de professores de ciências. Ciência \& Educação (Bauru), v. 17, n. 1, p. 35-50, 2011.

KELLER, P. F. O artesão e a economia do artesanato na sociedade contemporânea. Política \& Trabalho, v. 2, n. 41, 2014.

LIMA JÚNIOR, P. et al. Marx como referencial para análise de relações entre ciência, tecnologia e sociedade. Ciência \& educação. Bauru. Vol. 20, n. 1 (Jan./Mar. 2014), p. 175-194, 2014.

LINDEMANN, R. H. et al. Biocombustíveis e o ensino de Ciências: compreensões de professores que fazem pesquisa na escola. Revista Electrónica de Enseñanza de las Ciencias, v. 8, n. 1, p. 342-358, 2009. 
LOPES, A. C. Os parâmetros curriculares nacionais para o ensino médio e a submissão ao mundo produtivo: o caso do conceito de contextualização. Educação \& Sociedade, v. 23, n. 80, p. 386-400, 2002.

LOPES, A. C.; LÓPEZ, S. B. A performatividade nas políticas de currículo: o caso do ENEM. Educação em revista, v. 26, n. 1, p. 89-110, 2010.

LUTFI, M. Cotidiano e educação em química: os aditivos em alimentos como proposta para o ensino de química no segundo grau. ljuí: Unijuí, 1988.

LUTFI, M. Ferrados e cromados: produção social e apropriação privada do conhecimento químico. ljuí: Unijuí, 1992.

MARCONDES, M. E. R. et al. Materiais instrucionais numa perspectiva CTSA: uma análise de unidades didáticas produzidas por professores de química em formação continuada. Investigações em Ensino de Ciências, v. 14, n. 2, p. 281-298, 2016.

MELO, M. R.; VILLANI, A. A evolução de uma professora na formação de licenciandos de Química numa perspectiva sócio-ambiental. Investigações em Ensino de Ciências, v. 16, n. 2, p. 291-315, 2011.

MENDONÇA, P. C. C.; JUSTI, R. S. Ensino-aprendizagem de ciências e argumentação: discussões e questões atuais. Revista Brasileira de Pesquisa em Educação em Ciências, v. 1, p. 187-216, 2013.

NASCIMENTO, T. G.; VON LINSINGEN, I. Articulações entre o enfoque CTS e a pedagogia de Paulo Freire como base para o ensino de ciências.

Convergencia Revista de Ciencias Sociales, v. 13, n. 42, p. 95-116, 2006.

OLIVEIRA, L. et al. A contextualização no ensino de química: uma análise à luz da filosofia da linguagem de Bakhtin. Revista Ciências \& Ideias, v. 6, n. 2, p. 29-45, 2015.

RELATÓRIO DE ECONOMIA CRIATIVA 2010: economia criativa uma, opção de desenvolvimento. - Braślia: Secretaria da Economia Criativa/Minc; São Paulo: Itaú Cultural, 2012.

RONQUIM, C. C. Queimadas na colheita da cana-de-açúcar: impactos ambientais, sociais e econômicos. Embrapa Monitoramento por Satélite. Documentos, 2010.

SÁ, L. P.; QUEIROZ, S. L. Estudo de casos no ensino de química. Campinas: Editora Átomo, 2010.

SASSERON, L. H. Alfabetização científica, ensino por investigação e argumentação: relações entre ciências da natureza e escola. Ensaio 
Pesquisa em Educação em Ciências (Belo Horizonte), v. 17, n. spe, p. 49-67, 2015.

SANTOS, P. T. A. et al. Lixo e reciclagem como tema motivador no ensino de química. Eclética Química Journal, v. 36, n. 1, p. 78-92, 2018.

SANTOS, W. L. P. Contextualização no ensino de ciências por meio de temas CTS em uma perspectiva crítica. Ciência \& Ensino, v. 1, 2008.

SANTOS, W. L. P. Educação científica humanística em uma perspectiva freireana: resgatando a função do ensino de CTS. Alexandria: Revista de Educação em Ciência e Tecnologia, v. 1, n. 1, p. 109-131, 2008.

SANTOS, W. L. P.; MORTIMER, E. F. Concepções de professores sobre contextualização social do ensino de química e ciências. In: Reunião Anual da Sociedade Brasileira de Química, 22, 1999. Anais. Poços de Caldas: Sociedade Brasileira de Química, 1999.

SANTOS, W. L. P.; MORTIMER, E. F. Uma análise de pressupostos teóricos da abordagem C-T-S (Ciência-Tecnologia-Sociedade) no contexto da educação brasileira. Ensaio: pesquisa em educação em ciências, v. 2, n. 2, p. 133-162, 2002.

SANTOS, W. L. P. dos; SCHNETZLER, R. P. Função social: o que significa ensino de Química para formar o cidadão? Química Nova na Escola, n4, nov., p. 28- 34, 1996.

SILVA, L. F.; DE CARVALHO, L. Professores de física em formação inicial: o ensino de física, a abordagem CTS e os temas controversos. Investigações em Ensino de Ciências, v. 14, n. 1, p. 135-148, 2016.

SILVA, E. L. da; MARCONDES, M. E. R.; Visões de contextualização de professores de química na elaboração de seus próprios materiais didáticos. Ensaio Pesquisa em Educação em Ciências, v. 12, n. 1, p. 101, 2010.

SODRÉ, M. A máquina de Narciso. São Paulo: Cortez, 1990.

SOLINO, A. P.; GEHLEN, S. T. Abordagem temática freireana e o ensino de ciências por investigação: possíveis relações epistemológicas e pedagógicas. Investigações em Ensino de Ciências, v. 19, n. 1, p. 141-162, 2016.

SOUSA, R. S. de; ROCHA, P. D. P.; GARCIA, I. T. S. Estudo de caso em aulas de química: percepção dos estudantes de nível médio sobre o desenvolvimento de suas habilidades. Química Nova na Escola, São Paulo, v. 34, n. 4, p. 220228, 2012. 
PAZINATO, M. S.; BRAIBANTE, M. E. F. O estudo de caso como estratégia metodológica para o ensino de Química no nível médio. Revista Ciências \& Ideias, v. 5, n. 2, p. 1-18, 2014.

POZO, J. I.; CRESPO, M. A. G. A aprendizagem e o ensino de ciências - do conhecimento cotidiano ao conhecimento científico. Porto Alegre, Rio Grande do Sul, Artemed Editora, 2009.

VILLANI, A. e BAROLLI, E. Os discursos do professor e o ensino de ciências. ProPosições, v. 17, n. 1, jan./abr./2006.

VILLANI, C. E. P.; DO NASCIMENTO, S. S. A argumentação e o ensino de ciências: uma atividade experimental no laboratório didático de física do ensino médio. Investigações em ensino de Ciências, v. 8, n. 3, p. 187-209, 2016.

WARTHA, E. J.; FALJONI-ALÁRIO, A. A contextualização no ensino de química através do livro didático. Química Nova na Escola, v. 22, n. 2, p. 42-47, 2005.

WARTHA, E. J.; SILVA, E. L. da; BEJARANO, N. R. R. Cotidiano e contextualização no ensino de Química. Química Nova na Escola, v. 35, n. 2, p. 84-91, 2013.

ZAUITH, G.; HAYASHI, M. C. P. I. A influência de Paulo Freire no Ensino de Ciências e na Educação CTS: uma análise bibliométrica. Revista HISTEDBR On-line, v. 13, n. 49, p. 267-293, 2013.

Recebido em: 13 de março de 2019 Aprovado em: 20 de agosto de 2019 